\title{
Congestive cardiac failure: central role of the arterial blood pressure
}

\author{
St Cyres lecture 1986 \\ PETER HARRIS \\ From the Cardiothoracic Institute, University of London, London
}

SUMMARY A review of the history of our knowledge and understanding of the peripheral oedema of congestive cardiac failure points to the conclusion that an inability of the heart to maintain the arterial pressure is of central importance in this condition. Although the function of the circulation is to perfuse the tissues, the body monitors the adequacy of its perfusion, not through metabolic messengers carried from the tissues in the blood stream, but by sensing the arterial pressure; and the mechanisms evoked act to maintain the arterial pressure. In the short term this is achieved by autonomic regulation of the heart and blood vessels; in the longer term the arterial pressure is maintained through an increase in the blood volume by a retention of salt and water by the kidney. To support the latter process, intrinsic renal mechanisms are successively magnified by the renin - angiotensin-aldosterone system and by the activities of the sympathetic system and vasopressin. The natriuretic influence mediated through volume receptors and the release of atrial peptide is overruled by the arterial baroreceptors, so that the body maintains the arterial pressure at the expense of an increase in blood volume.

In these ways the syndrome of congestive cardiac failure may be regarded as one which arises when the heart becomes chronically unable to maintain an appropriate arterial pressure without support.

\section{Early concepts of cardiac failure}

Hope was probably the first to put forward a unified concept of backward failure. ${ }^{1}$ It was a concept based on pathology as well as physiology. The overworked ventricle first hypertophies and then dilates. As it dilates the blood gets dammed up behind it and an increased venous pressure is transmitted ultimately to the capillaries where oedema is formed.

The concept of backward failure was widely accepted until the last decade of the nineteenth century. But, in 1896, Starling, in his Arris and Gale lecture, reported experiments on dogs in which he injected oil into the pericardial sac. ${ }^{2}$ As the heart "failed" the pressure in the vena cava rose and that in the aorta fell. To decide whether this was accompanied by engorgement of the capillaries he placed a plethysmograph round one limb. This showed unequivocally that the volume diminished at the

Requests for reprints to Professor Peter Harris, The Cardiothoracic Institute, 2 Beaumont Street, London W1N 2DX. same time as the aortic pressure decreased and the vena caval pressure increased.

Starling concluded that in failure, although the pressure in the great veins rose, the pressure in the capillaries fell. If that were so, the only explanation that he could see for the loss of liquid from the blood into the tissues was an increased permeability of the capillaries; and the reason for their increased permeability had to be a loss of nutrition due to poor perfusion. "In heart disease the capillary pressure is not higher, but rather lower, than in a normal animal. The dropsy is entirely conditioned by the state of the capillary wall."

This theory of forward failure was championed by Mackenzie: "The blood passes through the capillaries at a slow rate, impairs their nutrition, and allows transudation to take place, which we call dropsy." So strongly did the great physician feel on this subject that there is an entry "Heart failure, backpressure theory, evil of," in the third edition of his textbook. "These views are the outcome of the discovery of auscultation," he writes, adding that in his 
opinion that discovery had "so far done more harm than good." 3

In the years that followed, attempts to investigate capillary permeability with dyes failed to demonstrate any increase during cardiac failure. Measurements of the protein composition of oedema liquid found that it was no different from normal interstitial liquid. And direct measurements of capillary pressure by the technique of Landis eventually showed that it was increased in cardiac failure. ${ }^{4}$ The normal pressure in digital capillaries held at the level of the heart fell from about $35 \mathrm{~mm} \mathrm{Hg}$ in the arteriolar limb to about $12 \mathrm{~mm} \mathrm{Hg}$ in the venous limb. In patients with congestive cardiac failure the pressure in the venous capillary limb averaged around $33 \mathrm{~mm} \mathrm{Hg}$.

\section{The blood volume}

The argument went literally backwards and forwards but by the second world war, when I became a medical student, backward failure was the standard teaching in London. And yet, looking back on notes which I made at the time, it did not seem to be a complete explanation. The circulation could be divided into two portions: the pulmonary and the systemic. Failure of one ventricle meant simply that blood was transferred from the portion in front of it to the portion behind it. The problem was that the volume of the systemic portion was ten times that of the pulmonary. In the case of the left ventricle, it was easy to imagine how blood transferred from the systemic portion could flood the pulmonary portion. But, when the right ventricle failed, the most that could be transferred into the systemic portion was the total volume of the pulmonary portion, estimated to be less than a pint. In no way could that account for the many pints of anasarca that, in those days, were removed by Southey's tubes.

Oedema of the lungs was, therefore, a special case. It could occur rapidly and could be readily explained on mechanical grounds. The problem was, and is, the slowly developing oedema of the rest of the body which is still generally referred to as right ventricular failure-this is the subject to which I shall address my comments during the remainder of this paper.

Another problem, pondered over in my notes, was the total blood volume. "Plethoric", all the old clinical masters had said. But if either the backward or the forward theory were correct the blood volume should diminish. Evidence suggesting the opposite had been accumulating since the first world war $^{5}$ and was greatly supported by Wollheim's extensive measurements. ${ }^{6}$

Early in the second world war Isaac Starr pub- lished the work that seemed to point in the right direction. He made a mechanical model which consisted of two pumps, designed to obey Starling's law, connected by pulmonary and systemic circuits the volume and resistance of which could be adjusted. ${ }^{7} \mathrm{He}$ found that when he made one or both of the pumps "fail" he could reproduce the haemodynamic effects of cardiac failure only if he increased the circulating volume or diminished the circulatory capacity. From this he elaborated his theory of the "static" pressure in the circulationthe pressure which existed throughout the circulation when the pumps were stopped. Extending these ideas to man he found that the "static" pressure measured in newly dead corpses was much higher when there had been cardiac failure. ${ }^{8}$

Starr's observations strongly supported the evidence that capillary pressure was raised in congestive failure. But at the same time they showed that the "static pressure" in a person without congestive failure was lower than the pressure in the venous limb of the capillaries, which lent support to Starling's conclusion that when the cardiac output was abruptly reduced the capillary pressure fell.

Starling's conclusion also receives support from a commonplace observation. At the time of death the heart stops completely and yet tissue oedema does not occur in the succeeding hours even in the areas, for instance, round the eyes, where the tissue is lax and liable to accumulate liquid easily. This state of affairs is explained by a "static pressure" which is considerably lower than the colloid osmotic pressure of the plasma.

So Starling was probably right in believing that the capillary pressure fell in his dogs. His mistake was to transfer this observation to patients with cardiac failure. "The dogs deceived him", as East said of Lewis's work on bundle branch block.

\section{The cardiac output}

In the history of cardiology the period of the second world war is notable, above all, for the introduction by Cournand and Richards of the technique of cardiac catheterisation; this made immediately available the measurement of the cardiac output more accurately and securely than had previously been possible. Many early studies showed the cardiac output to be reduced in congestive cardiac failure, which would have pleased both the backward and the forward failure theorists. But shortly after came the discovery of a group of conditions that clinically appeared to be associated with congestive cardiac failure but in which the cardiac output was increased. The causes of this "high output failure" included anaemia, thyrotoxicosis, Paget's disease of 
bone, arteriovenous fistulas, cor pulmonale, and beriberi.

Here was near disaster for the backward failure theorists and a serious dilemma for the forward failure theorists. If failure was caused by a diminished supply of blood to the body how could the same syndrome occur with a greatly increased blood supply? The answer was the definition which, with small changes in wording, appears today in every text book of cardiology: "a state in which the heart fails to maintain an adequate circulation for the needs of the body ..."9

\section{Peripheral metabolism}

What was left undefined was the nature of the needs of the body. What was this mysterious metabolic requirement, the lack of which led to oedema?

Fuels for cells consist of oxygen, glucose, and fatty acids. Calculations of the turnover rate of these three fuels in the blood show that the turnover rate of oxygen is five or six times as high as that of the other two. Glucose and fatty acids enter the blood through local streams which subsequently join the main flow. Only for oxygen is the point of entry dependent on the total cardiac output. The most critical need of the body referred to in the definition must, therefore, be the need for oxygen.

But if in patients without metabolic disturbances the circulation becomes inadequate to supply the needs of the body it follows that the oxygen uptake is diminished. Yet the early studies using the Fick principle had clearly shown that this was not so. ${ }^{10}$

\section{The law of the heart}

History is not one main road and we shall leave the blind alley into which much of the world of cardiology still finds itself and retrace our steps back to 1915-the year of the law of the heart. "... The mechanical energy set free on passage from the resting to the contracted state depends ... on the length of the muscle fibre. This simple formula serves to 'explain' the whole behaviour of the isolated mammalian heart."11 The simplicity of the law aided by the sheer arrogance of its title gave it an immediate authority. It was widely welcomed by the backward failure supporters although, as we have seen, Starling himself was firmly committed to forward failure. Note how Starling limited it to the isolated heart. This important and severe limitation has been widely disregarded.

The law takes no account of the processes of hypertrophy and dilatation which are so important in clinical disease. It ignores, also, the important role played by the autonomic system. As Hamilton and
Richards were later to point out, "Without the coordinating stimulus of the central nervous system and the hormonal control governed by this system, the truly isolated heart seems to vary its pumping function between that of a heart in a normal resting animal and that of a heart in an animal moribund in the last stages of shock."12

\section{The autonomic nervous system}

The influence of the autonomic nervous system on the heart was, of course, known to Starling, and much of our present understanding of it dates from the nineteenth century. However, it took a surprisingly long time before the relation between Starling's law and sympathetic drive was elucidated. This was the contribution of Sarnoff and Berglund who showed that a heart could develop a whole family of Starling's curves depending on the degree of sympathetic stimulation. ${ }^{13}$

An entirely new step forward was taken by Chidsey, working in Braunwald's laboratory. He showed that the concentration of noradrenaline in the plasma increased much more in patients with congestive failure during exercise than it did in normal people. ${ }^{14}$ The daily excretion of noradrenaline in the urine was also increased in these patients. ${ }^{15}$

The influence of the sympathetic system extended not only to the heart but throughout the vascular system. At about this time Donald, Wade, and Bishop were studying the redistribution of blood flow to various regions of the body in cardiac patients. ${ }^{16}$ They showed that the redistribution of flow in patients with cardiac failure was similar to the redistribution seen during physical exercise in normal people. It comprised a reduction in blood flow to the kidneys, gut, and skin, with preservation of flow to the myocardium and skeletal muscle. The vasoconstrictor influence of the sympathetic system on the renal circulation is especially important. In heart failure the increased sympathetic activity causes the renal blood flow to decrease disproportionately to the cardiac output.

\section{Control of the cardiovascular system by the central nervous system}

In 1870 Dittmar, working in the laboratories of the self-effacing Carl Ludwig, found that the increase in blood pressure caused by stimulation of the sciatic nerve was retained in animals with pontine transection but abolished when the medulla was destroyed. ${ }^{17}$ Owsjannikow, from the same laboratory, studied successive transections of the brain stem and discovered that the blood pressure began to fall at the caudal border of the inferior colliculi 
and reached the low pressure of a spinal animal with transections below the obex. ${ }^{18}$ Dittmar's further studies located the region responsible for maintenance of the blood pressure in the ventral region of the lateral reticular formation. ${ }^{19}$

Later researches have shown a widespread involvement of the reticular formation of the brain stem in the coordination and modulation of cardiovascular responses, and this led to the general view that vasomotor control was diffusely mediated rather than located in a specific area. Recent findings have, however, indicated a specific and important role of a region in the ventrolateral medulla-the site first proposed by Dittmar over a hundred years ago. The first clue came from observations that the application of a cold probe ${ }^{20}$ or pharmacological agents ${ }^{21} 22$ to a specific area of the ventrolateral surface of the medulla could cause a precipitous fall in blood pressure. These observations suggested the existence of a minute localised vasomotor region lying very close to the surface of the medulla. Subsequent studies have identified it as the rostral portion of the ventrolateral reticular nucleus, corresponding to a group of adrenaline-synthesising cells usually referred to as $\mathrm{C} 1$ neurones. ${ }^{23}$ Neurones of the $\mathrm{Cl}$ area project to the autonomic neurones of the intermediolateral column of the spinal cord. ${ }^{24}$ Electrical or chemical stimulation of the $\mathrm{Cl}$ area leads to an increase in arterial pressure and heart rate and increased concentrations of catecholamines and vasopressin in the plasma. ${ }^{25}$ Electrolytic lesions of the area cause a fall in arterial pressure to levels similar to those of a spinal preparation. ${ }^{26}$ The caudal portion of the ventrolateral reticular nucleus consists of cells which contain noradrenaline (Al area). They project to more rostral cardiovascular regions, including the $\mathrm{Cl}$ area and have a depressant effect on the blood pressure. $^{2728}$

At the beginning of this century, afferent fibres travelling in the vagus and glossopharyngeal nerves were traced to the nucleus tractus solitarius. ${ }^{29}$ In 1932 Bronk and Stella demonstrated the existence of the baroreceptors which sense the stretch of the arch of the aorta and the carotid sinus caused by the arterial blood pressure. ${ }^{30}$ The afferent baroreceptor impulses end in the nucleus tractus solitarius from which controlling relays pass to the $\mathbf{C l}$ area of the ventrolateral medulla to inhibit its tonic discharge to the preganglionic sympathetic neurones of the intermediolateral column of the spinal cord. At the same time relays pass from the nucleus tractus solitarius to the nucleus ambiguus and the dorsal nucleus of the vagus from which parasympathetic influences are projected through the vagus nerve. In this way, an increased arterial pressure reflexly diminishes cardiovascular sympathetic tone and, at the same time, stimulates parasympathetic activity to slow the heart.

Similar stretch receptors, the "cardiopulmonary volume receptors", give rise to afferent discharges which also travel through the vagus to the nucleus tractus solitarius. These are stimulated by distension of the atrium and other low pressure regions and act to inhibit the sympathetic outflow from the medulla.

Control of the heart rate, cardiac output, and blood pressure is mediated also by regions of the mid-brain, hypothalamus, and cerebral cortex, some of which have been described together by Hilton as organising the "defence reaction." 31 This physiological response is made up of an increased arterial pressure with an increased cardiac output, vasoconstriction in the gut, skin, and kidney, and vasodilatation in skeletal muscle.

\section{Neuroendocrine mechanisms}

The relation between the hypothalamus and the pituitary is central to the neuroendocrine control of the body. The posterior pituitary is an extension of the brain into which magnocellular neurones from the paraventricular and supraoptic nuclei descend, carrying oxytocin and vasopressin. Vasopressin has both antidiuretic and vasoconstrictive properties, although the effects of the latter on the arterial pressure are normally concealed by the action of the baroreceptors. In addition to its magnocellular population, the paraventricular region of the hypothalamus contains many parvocellular neurones. Some of these project to the median eminence $^{32}$ and are presumably concerned with the neural control of anterior pituitary hormone secretion through the hypophysial long portal system. Other parvocellular neurones of the paraventricular nucleus project to the nucleus tractus solitarius, the ventrolateral medulla, and directly to the intermediolateral column of the spinal cord. ${ }^{33-35}$ There are reciprocal connections between the paraventricular nucleus and the nucleus tractus solitarius and $\mathrm{A} 1$ area $^{36}$ and, through these, the paraventricular nucleus may modulate the baroreceptor arc.

Many peptides are synthesised within the central nervous system. Several of them, including angiotensin II, vasopressin, neurotensin, calcitonin generelated peptide, and neuropeptide $Y$, have powerful vasomotor effects elsewhere in the body, but their function in the brain is largely unknown. The bloodbrain barrier is, in general, impervious to peptide molecules in the plasma, but, in certain small areas of the ventricular system, the capillary endothelial cells are fenestrated. These "circumventricular" 
organs may, therefore, be a pathway through which plasma peptides, such as angiotensin II and vasopressin, can influence the central nervous system.

In addition to the influence of the hypothalamus on the release of anterior and posterior pituitary hormones the central nervous system exercises a control over the release of renin from the kidney (either directly through $\beta$ receptors in the afferent arteriole or indirectly through renal arterial vasoconstriction) and over the release of adrenaline and noradrenaline from the adrenal medulla.

\section{Modifications of the autonomic nervous system}

Evidence has been put forward that the baroreceptor response is diminished in patients with heart failure. ${ }^{3738} \mathrm{~A}$ similar apparent diminution in baroreceptor response has been reported in normal people during exercise. ${ }^{3940}$ In both cases it seems likely that this is an expression of a new setting of the medullary centres which diminish vagal outflow at the same time as they increase sympathetic outflow.

Changes in the autonomic system also occur in the heart itself. There is a diminished response of afferent nerve fibres to stretch in the atrium ${ }^{41}$ which may be due to an increased rigidity of the atrial wall or changes in the structure of the afferent endings. ${ }^{42}$ A notable change in the myocardium is a profound decrease in the content of noradrenaline. ${ }^{43-45}$ Its cause has been debated (see Rupp and Jacob ${ }^{46}$ for review). In our experiments (unpublished data) the diminution in content has been specifically associated with failure. In the presence of ventricular hypertrophy without failure the content of noradrenaline has remained unchanged while its concentration has decreased simply because the volume of myocytes has increased. The response of the ventricle to postganglionic sympathetic nerve stimulation has been found to be reduced in dogs with cardiac failure. ${ }^{47}$ This may in part be due to the diminished stores of noradrenaline but there is also evidence that there is a decrease in the density of $\beta$ adrenergic receptors in the myocardium. ${ }^{48}$

\section{The kidneys}

Soon after Starr's observations on "static pressure" Warren and Stead followed the course of events in patients with heart failure whose cardiac treatment had been stopped. ${ }^{49}$ They found that the body weight and plasma volume started to increase before they could detect any increase in venous pressure. By now it was clear that the formation of oedema and the expansion of the plasma volume implied an increase in the volume of the extracellular space. It is remarkable how long it took for this simple fact, so obvious to anyone who had seen the patients bloated with oedema, to become formally part of the concept of failure.

Now, therefore, attention swung to the kidney. The scanty concentrated urine had been known since the time of Hippocrates and the routine testing for "chlorides" in the urine with silver nitrate had long been used to teach students that chloride was being retained. Merrill showed that the retention of sodium in the urine was associated with a striking diminution in the renal blood flow. 50 "Evidence of 'forward failure' as primary cause of edema" is the subtitle of the paper. But now "forward failure" refers to the kidneys not to vascular endothelium.

At first it was thought that a simple decrease in glomerular filtration rate in the presence of normal tubular reabsorption was sufficient to account for the retention of sodium ${ }^{51}$ but more a careful mathematical analysis showed that there was a mysterious increase in tubular reabsorption. 5253

In fact, the decrease in glomerular filtration was less than the decrease in renal blood flow and was not obvious until cardiac failure became clinically severe. ${ }^{52}$ In dogs with constriction of the thoracic inferior vena cava, glomerular filtration was actually increased in the presence of severe sodium retention. ${ }^{54}$ This was unlike what was known to happen when perfusion diminished in the isolated kidney. ${ }^{55}$ Here, renal blood flow and glomerular filtration were both maintained as the perfusion pressure was reduced from 180 to $80 \mathrm{~mm} \mathrm{Hg}$ while below that pressure glomerular filtration fell more precipitously than renal blood flow so that the filtration fraction decreased. The high filtration fraction of cardiac failure implied that the post-glomerular vascular resistance was increased disproportionately to the pre-glomerular resistance. Barger suggested that this would lead to an increased colloid osmotic pressure in the peritubular capillaries which would promote tubular reabsorption of salt and water. ${ }^{56}$ This mechanism (originally conceived by Carl Ludwig ${ }^{57}$ ) did not receive immediate acceptance; but subsequent work has led to the view that it is an important factor regulating reabsorption from the proximal tubule and there is evidence that it functions in this way in congestive cardiac failure. ${ }^{5859}$

There is in addition abundant evidence of enhanced distal reabsorption of sodium both in high output failure ${ }^{6061}$ and in low output failure. ${ }^{62-64}$ This is the region where aldosterone and, probably, atrial natriuretic factor exert their effects.

\section{Renin-angiotensin-aldosterone}

The first clue to the importance of aldosterone in 
cardiac failure was found by Singer and Werner who observed that the urine of patients with failure contained a sodium-retaining substance. ${ }^{65}$ This was soon identified as aldosterone. ${ }^{66}$ Evidence of an increased secretion of aldosterone into the blood grew both in patients and in experimental animals. ${ }^{67}$ When one adrenal was removed and the other transplanted to the neck the response of aldosterone to constriction of the thoracic inferior vena cava was normal. ${ }^{68}$ Crossed circulation of blood from a dog with a constricted vena cava to a normal dog caused an increased secretion of aldosterone. ${ }^{69}$ These studies showed that the stimulus to the secretion of aldosterone was humoral. Further studies with nephrectomy and the injection of renal extracts showed that the agent came from the kidney, and it was only a short step to identify it as renin and the immediate humoral agent as angiotensin 1 II. $^{70}$ In fact Merrill and his colleagues had already reported an increased concentration of renin in renal venous blood of patients in cardiac failure in 1946, but its significance had gone unrecognised.

The increased release of renin during renal ischaemia had been known since Goldblatt et al's original observations. ${ }^{71}$ Now this mechanism could be seen to be operating in cardiac failure. However, although the renal blood flow was known to be decreased in cardiac failure, the control of the release of renin from the juxtaglomerular cells was found to depend on the mean arterial perfusion pressure rather than on blood flow. ${ }^{72}$ This supported Tobian et al's theory that the release of renin was directly regulated by the degree of stretch of the walls of the afferent glomerular arterioles ${ }^{73}$; subsequent work has confirmed this mechanism. In addition, changes in the concentration of sodium chloride ions in the region of the macula densa affect the rate of release of renin. This mechanism underlies the effects of a dietary restriction of salt and of diuretics which act by inhibiting the reabsorption of chloride in the ascending limb of the loop of Henle. The direct effects of perfusion pressure, however, can be shown to operate when the macula is excluded. ${ }^{74}$

The relation between renal arterial pressure and plasma renin activity shows that little renin is released as the mean renal arterial pressure falls from 100 to $85 \mathrm{~mm} \mathrm{Hg} .{ }^{75}$ Thereafter the increase in plasma renin activity increases linearly down to pressures of $50 \mathrm{~mm} \mathrm{Hg}$. This implies that the intrinsic afferent arteriolar stretch receptor system is, by itself, relatively unresponsive to a small fall in arterial pressure. The responsiveness of the system is, however, greatly increased by adrenergic stimuli, which act by increasing the threshold for renin release $^{75}$ so that a small decrease in arterial pressure can evoke a substantial release of renin. Both stimulation of renal sympathetic nerves and bloodborne adrenergic agents are effective and act through $\beta$ receptors.

Electrical stimulation of the dorsolateral pons ${ }^{76}$ and the lateral hypothalamus ${ }^{77}$ evoke renin release that can be prevented by denervation of the kidneys. The afferent limb of the reflex arises from the arterial baroreceptors and the cardiopulmonary "volume" receptors described above. ${ }^{78}$ The two systems may be shown to conflict under experimental conditions ${ }^{79}$ and, as discussed later, presumably do so in cardiac failure.

The operation of the sympathetic system is not necessary for the release of renin by the kidney in response to a decreased perfusing pressure but renin release is greatly enhanced by sympathetic stimulation. Thus the reflex control of the release of renin seems to be particularly important when arterial pressure changes slightly with physiological conditions such as posture ${ }^{80}$ and exercise. ${ }^{81}$ Even psychological stimuli have been found to increase plasma renin activity. ${ }^{82}$ Careful early studies had shown that the sympathetic system, the baroreceptors, and volume receptors and even the brain were not necessary to the renin-aldosterone response during constriction of the thoracic inferior vena cava in animals. ${ }^{67}$ This gave rise to the view that the nervous system was not a factor. But something which is not necessary may still be used, and the present evidence suggests that the nervous system has an important role in human disease in which the initial degrees of cardiac disability are likely to be less severe.

In addition to stimulating the secretion of aldosterone, angiotensin II has other important properties in cardiac failure; it is a powerful vasoconstrictor, it enhances adrenergic neuroeffector transmission, and it is concerned with the sensation of thirst. Its constrictor properties are important in maintaining the arterial pressure and may be the cause of the particular increase in post-glomerular vascular resistance. ${ }^{83}$

Early measurements of both aldosterone and renin activity in the plasma were confusing. It seemed that both were increased in some patients but were normal in others. The explanation came from the experiments on dogs carried out by Watkins et al ${ }^{84}$ They showed that after constriction of the pulmonary artery or inferior vena cava "the initial response was a reduction in blood pressure, a rise in plasma renin activity, plasma aldosterone, and water intake, and nearly complete sodium retention. In the days after moderate constriction plasma volume and body weight increased (with development of ascites and oedema); blood pressure, sodium excretion, plasma renin activity, and plasma aldosterone 
returned to normal. In animals in which blood pressure was not restored, plasma renin activity and plasma aldosterone remained elevated throughout the period of constriction."

This view of the endocrine response as something which might be transient, rather than sustained, was an important step forward. The renin-angiotensinaldosterone system responds both in low output and in high output failure ${ }^{85}$ and the considerable number of reports on the beneficial effects of converting enzyme inhibitors testifies to the great importance of this system in clinical cardiac failure.

\section{Arginine vasopressin}

Early studies showed that the urine of patients with cardiac failure contained an antidiuretic substance ${ }^{8687}$ but it was some years before analytical techniques were adequate to show that plasma vasopressin concentration was increased. ${ }^{88}$ This finding was consistent with the highly concentrated urine passed in cardiac failure, and the studies of Anderson et al showed the role of vasopressin and the mechanism through which its release is stimulated. ${ }^{89}$ Their experiments were carried out on dogs subjected to acute obstruction of the thoracic inferior vena cava. If the renal arterial pressure was held constant there was a fall in cardiac output and aortic pressure, a fivefold increase in urinary osmolality, and a dramatic reduction in free water clearance. Hypophysectomy greatly attenuated the response of urinary osmolality and free water clearance if renal arterial pressure was held constant but, if renal arterial pressure was allowed to fall, there was a considerable decrease in free water clearance. From this it could be concluded that the increase in urinary osmolality was due almost entirely to vasopressin, while the decreased free water clearance was also partly determined by a diminished delivery to the distal nephron. Constriction of the inferior vena cava had no effect on urinary osmolality or free water clearance in dogs that had intact hypophyses but denervation of the baroreceptors. This indicated that the release of vasopressin during vena caval constriction was stimulated by a reduction in afferent baroreceptor impulses.

Constriction of the inferior vena cava, however, is unlike intrinsic failure of the heart in that the pressures affecting the low-pressure "volume" receptors are diminished. ${ }^{84}$ The studies of Anderson et $a l^{89}$ therefore suggest that in patients with cardiac disease the stimulatory effect of a low arterial pressure on the release of vasopressin overrides the inhibitory effect of atrial distension. Such a predominance of arterial baroreceptors over atrial stretch receptors appears to be normal in primates. ${ }^{9091}$ It is unlikely that the increased release of vasopressin in congestive failure is mediated through osmoreceptors since the plasma osmolality is generally decreased rather than increased.

\section{Atrial natriuretic peptide}

Early electron microscopical studies had shown the presence of specific granules in atrial myocytes, but their function was not suspected until de Bold showed that the numbers of granules varied with changes in water and electrolyte balance. ${ }^{92}$ Two years later he showed that atrial extracts had a natriuretic effect. ${ }^{93}$

The active principle has now been identified as a polypeptide and its amino acid sequence has been determined. ${ }^{9495}$ In the atrium it appears to be formed from the cleavage of a larger precursor molecule. ${ }^{96}$ Atrial natriuretic peptide is released in response to a high atrial pressure ${ }^{97}$ and the plasma concentration of the peptide has been found to be increased in patients with congestive cardiac failure. ${ }^{98}$

The natriuretic effect appears to be located in the distal tubules and collecting ducts. ${ }^{99}$ In the whole animal the effects of the peptide may be partly mediated through an inhibition of the secretion of aldosterone and of the release of renin. In addition to its effects on the kidney, atrial natriuretic peptide has been shown to be a vasodilator. ${ }^{100}$

Distention of the atrium causes a release of natriuretic peptide and at the same time stimulates nerve receptors that lead to an inhibition of sympathetic activity and a diminished release of renin. The two mechanisms, therefore, act together to lower systemic vascular resistance and increase the excretion of sodium. But, clearly, the natriuretic and vasodilator effects of the peptide in patients with cardiac oedema are quite outweighed by the sodium retention and vasoconstriction caused by sympathetic stimulation and activation of the reninangiotensin-aldosterone system. It follows also that the stimulation of the sympathetic-renin-angiotensin-aldosterone system by the low arterial pressure outweighs its inhibition by cardiopulmonary volume receptors.

\section{Retention of saline is harmful}

It may be supposed that the body reacts to a failing heart in a manner which will be beneficial. For instance, the retention of water by the kidneys may ? be seen as a way of increasing the filling of the heart and, thereby, its output. And yet diuretics are probably the most efficacious treatment we have. Vasoconstriction should maintain the blood pres- 
sure and preserve flow to vital organs. Yet vasodilators are now widely used to treat cardiac failure. Similarly it might be argued that angiotensin II and aldosterone are beneficial; yet captopril and spironolactone are found to be helpful.

It seems that every time we thwart nature's intentions, the patient improves. The explanation of this paradox is that the processes which are evoked during cardiac failure originally evolved for some quite different purpose. ${ }^{101}$

Cardiac failure is a rare event. So exotic a condition would not have any perceptible effect on the survival of the species. The powerful mechanisms that we find in cardiac failure are more likely to have evolved to deal with circumstances vital to everyday preservation. Of these circumstances the two most obvious are physical exercise and trauma.

Unpublished studies carried out with colleagues at the University of Brescia have shown that during exercise plasma concentrations of several hormones increase in a sequential fashion: noradrenaline and adrenaline, vasopressin, and atrial natriuretic peptide, followed by renin activity and aldosterone. Measurements on patients with untreated myocardial infarction also showed an increase in all these factors.

The neuroendocrine-renal response in both these conditions is, therefore, similar to the response in congestive cardiac failure. The important difference is in the length of time over which the stimulus is maintained-minutes or hours for exercise, hours or days for shock, weeks or months or years for cardiac failure. The mechanisms that may be necessary for exercise or for survival in injury are harmful when maintained over prolonged periods because they lead to the retention of saline in the body. For the reason why the excessive retention of saline is harmful we have to go back far into evolutionary history to the emergence of air-breathing animals ${ }^{101}$ since it is the air-breathing lung that is so susceptible to flooding.

\section{Cardio-neuro-endocrine links}

Apart from the complicating presence of pain, the condition of acute myocardial infarction is a highly appropriate model of the immediate neuro-humoral response of the body to a suddenly diminished pumping capacity of the heart. Already there is evidence of both increased sympathetic activity and its associated endocrine response.

We have already discussed the links between a stimulation of the sympathetic system and the endocrine response. But what is the link between a diminished cardiac output and the stimulation of the sympathetic system?
There appear to be two main possibilities: metabolic and mechanical. First, the low cardiac output may lead to underperfusion of the tissues that release some intermediary substance into the blood stream. Second, the purely mechanical effects of a low cardiac output may give rise to the requisite afferent impulses.

Is there ischaemia of the tissues in cardiac failure? We can say, as noted above, that the oxygen uptake of the body is undiminished at rest in congestive failure; but the oxygen content of the mixed venous blood is abnormally low so that, in general, the tissues must be functioning at a lower $\mathrm{Po}_{2}$ than normal. Nevertheless, the blood lactate in such patients is normal at rest ${ }^{102}$ and we can, therefore, conclude that, at rest, the supply of oxygen is not rate-limiting for ATP synthesis in the body as a whole.

On the other hand, the concentration of lactate in the blood increases to a greater extent than normal during exercise in cardiac patients. ${ }^{102}$ This may, in part, be due to the glycolytic action of catecholamines (whose presence in excess during exercise of patients with cardiac failure has already been discussed) and in part to an inadequate supply of oxygen. In the latter case, it might be reasonable to suppose that a metabolic messenger was released into the blood stream and stimulated either the heart or the central nervous system at some distant point.

Experimental evidence, however, is entirely against such a hypothesis. First, the increase in heart rate occurs within a cardiac cycle, ${ }^{103}$ an interval much shorter than the circulatory time required for the messenger. Second, substantially the same increase in heart rate and arterial pressure occurs in normal subjects whether or not the exercising limb is rendered ischaemic. ${ }^{104-106}$

There are, however, two organs in which a reduction in blood flow may have a specific effect-the kidney and the brain. A decrease in renal perfusion pressure associated with a reduced cardiac output may itself stimulate the release of renin and favour the retention of saline by the kidney. The reduction of renal blood flow in cardiac failure is, however, proportionally greater than the reduction in cardiac output. ${ }^{16}$ This is an indication of the importance of the increased sympathetic activity which magnifies the release of renin, as discussed above. A further, and little considered, result of a reduced renal blood flow may be an increased production of erythropoietin, since there is an increase in total red cell volume as well as plasma volume in cardiac failure. ${ }^{107}$

The vasopressor effects of severe ischaemia of the brain stem have been known since the last century. These effects have been shown to be mediated through the rostral ventrolateral medulla; lesions in 
this area abolish the effects. ${ }^{108}$ Cerebral blood flow tends to be protected in cardiac failure ${ }^{16}$ and brain stem ischaemia has to be severe to have vasopressor effects, so that the operation of this mechanism in cardiac failure remains uncertain.

In the original experiments of Alam and Smirk ${ }^{104105}$ discussed above, both the heart rate and the arterial pressure remained raised after exercise so long as the cuff stopping blood flow was inflated. Subsequent investigators have confirmed this observation with regard to the blood pressure but not always with regard to the heart rate. ${ }^{109}$ Alam and Smirk suggested that the afferent impulses arose from stimulation by some metabolite released from exercising muscle fibres. Subsequent investigations have pointed to potassium ions as the likely local mediator. ${ }^{110}$

The existence of a reflex mechanism arising from exercising muscles was shown directly in cats by Coote et al. ${ }^{111}$ Stimulation of the ventral root causing tetanic contractions of the hind limb was accompanied by an increase in the heart rate and arterial pressure. The cardiovascular response was not affected by dividing nerves to neighbouring joints or skin but was abolished by neuromuscular blockade or by cutting the dorsal roots. The afferent impulses travel through small, slowly conducting fibres with free nerve endings. ${ }^{109112}$ Some of these afferent fibres relay directly to the nucleus tractus solitarius ${ }^{113}$ and may, therefore, be responsible for the re-setting of the baroreflex arc which allows a moderate increase in arterial pressure during exercise. It will be remembered that Dittmar's experiments showed that the hypertension caused by stimulation of the sciatic nerve was retained despite transection at the level of the pons. ${ }^{17}$ In addition to such clear cut evidence of a cardiovascular influence of muscle afferents, there is evidence, albeit less strong, that influences from the cerebral cortex also have a role. ${ }^{109}$

The experiments of Alam and Smirk ${ }^{105}$ and others, quoted above, not only demonstrate the existence of a cardiovascular reflex from exercising muscle but also show that this reflex is unaffected by ischaemia of the muscle. There is, therefore, no reason to believe that the increased sympathetic response to exercise in cardiac patients is caused by an increased afferent input to the medullary centres. Cortical and other higher influences may be operating in evoking the defense reaction in these distressed patients. Similarly more general somatosensory afferents (for instance associated with dyspnoea or exhaustion) may have a direct influence on the reticular formation of the brain stem. ${ }^{114115}$ Both these latter influences may act to re-set the central baroreflex mechanism, both during exercise and at rest.

By far the most obvious way, however, in which a reduced cardiac output will magnify the sympathetic outflow, during rest and exercise, is through the vascular stretch receptors. And, here, the influence of the arterial baroreceptors must dominate, since the distension of the cardiopulmonary portion of the circulation will inhibit, rather than stimulate, the sympathetic outflow.

\section{A condition in which the cardiac output is inadequate to maintain the arterial pressure}

All these different lines of argument converge on the conclusion that control of the arterial pressure is the key link in the process of congestive cardiac failure. Present day opinion follows the view that in cardiac failure the cardiac output is insufficient for the metabolic needs of the body. But the needs of the body are, as we have seen, being met. Neither is there any evidence that the disturbances in energy pathways which may be required to maintain these needs lead to some blood borne messenger or to any increase in the afferent input from the limbs to the central nervous system.

Of course, the purpose of the circulation must be to provide perfusion to the tissues. But the body assesses the adequacy of the circulation by sensing the arterial pressure and not through metabolic messengers from the tissues. The arterial pressure is sensed by the juxtaglomerular cells and by the baroreceptors, and the sympathetic outflow which results from a reduction of baroreceptor input magnifies the response of the juxtaglomerular cells.

In this way, also, the mechanism of high output failure becomes apparent. All such patients have an abnormally low systemic vascular resistance either from vasodilatation or from arteriovenous shunts. Vasodilatation might be supposed to lead to oedema because the pressure at the arterial end of the capillary may be increased. This may well be a factor in some instances, but it cannot apply to the patients with arteriovenous communications. The common factor is the tendency to low blood pressure. Closure of an arteriovenous fistula causes an increased blood pressure and a prompt natriuresis. ${ }^{116}$ The difference between high output and low output failure is the difference in the ability of the heart to respond to the increased sympathetic drive.

Oedema is commonly associated with vasodilator treatment and may also be explained in this way. The oedema of cor pulmonale is always associated with the retention of carbon dioxide, which is a powerful vasodilator. In addition, a raised $\mathrm{PCO}_{2}$ in the cerebral circulation specifically stimulates the vasomotor sympathetic outflow. 
Hypertension and cardiac failure: common ground

Scientific and clinical specialisation alike have led to a world wide separation between those whose interest is primarily the blood pressure and those whose interest is primarily the heart: different societies, different journals. What is astounding is that exactly the same neurohumoral mechanisms are being studied independently by both groups. One group believes that these mechanisms are important in the control of the blood pressure; the other that they are important in cardiac failure. This paradox seems to have gone unremarked but is at once understandable if control of the blood pressure is the determining factor in cardiac failure.

\section{Arterial pressure, cardiac output, and exercise}

A look back over evolutionary history shows that the arterial pressure and the cardiac output took a sudden jump together when the warm-blooded animals emerged. ${ }^{101}$ With a high cardiac output and a superior air-breathing respiratory apparatus the mammals and birds were able to make full use of the energy available from oxidation in their red muscles. In this way they have developed the surpassing capacity for physical activity which has been a main origin of their success. For this purpose the circulation has to provide for a sudden massive increase in blood supply to the exercising muscles. This is achieved by a great capacity for an increased output and by vasodilatation in the exercising muscle and vasoconstriction in other regions.

I have argued elsewhere that it is these requirements of physical exercise which have necessitated the extraordinarily high arterial pressure of the mammals and birds. ${ }^{101}$ The combination of a high resting arterial pressure, together with an immense capacity for vasodilatation in skeletal muscle, allows a sudden massive increase in cardiac output with only a moderate increase in left ventricular emptying pressure. Thus the links between the cardiac output and the arterial pressure are archetypal and have their origins in the requirements for physical activity.

It may not, therefore, be surprising that the effects of physical exercise are specifically important in patients with a limited cardiac output. The therapeutic effect of rest in such patients was well known to our predecessors but has largely been forgotten by a generation obsessed with the cult of physical fitness. Physical exercise, as we have seen, evokes the same neuroendocrine response as is found in cardiac failure and, as judged by the concentration of plasma noradrenaline, the response to physical exercise is especially increased in cardiac patients.

During exercise, as discussed above, afferents from the exercising limbs and, probably, commands from higher centres re-set the medullary cardiovascular control system to permit an increased heart rate and arterial pressure. The diseased heart is unable to increase its output to the normal extent in response to autonomic control. During exercise, therefore, it is unable to increase the arterial pressure to the extent demanded by the medullary control system. The massive and largely locally mediated vasodilatation in the exercising muscles may even lead to a fall in arterial pressure. In the absence of an adequate modulatory baroreceptor input, the inhibitory influence of the nucleus tractus solitarius on the vasomotor elements of the reticular formation and perhaps specifically the $\mathrm{Cl}$ area may be presumed to be diminished so that the outflow to the preganglionic sympathetic neurones of the intermediolateral column of the spinal cord is increased.

The neuroendocrine response in congestive failure may well, therefore, be intermittent, according to the state of physical activity of the patient. This would in part explain why isolated blood samples may fail to show abnormal concentrations of hormones and why a chronic re-setting of the baroreceptor arc does not seem to occur.

Finally, it will be noted that all the changes in the peripheral autonomic system, reviewed above, will exacerbate the condition of congestive failure. Diminution of the baroreceptor response will reduce the inhibitory control which this exerts on the vasomotor centres. A decreased responsiveness of atrial receptors will reduce the afferent input whereby a distended atrium reduces sympathetic outflow. A lack of responsiveness of the myocardium to postganglionic sympathetic stimulation will reduce the increase in output that is necessary to maintain the blood pressure.

\section{Conclusion}

The evolution of a high cardiac output in the warmblooded animals has provided a surpassing capacity for physical activity supported by oxygen. The oxygen uptake of exercising muscles is met by a massive capacity for local vasodilatation and by an increase in cardiac output. The co-evolution of a high resting arterial pressure permits the increase in cardiac output to take place during exercise with a relatively stable left ventricular emptying pressure.

Although the function of the circulation is to perfuse the tissues, the body monitors the adequacy of its perfusion, not through metabolic messengers carried from the tissues in the blood stream, but by 
sensing the arterial pressure. A damaged heart becomes progressively less able to maintain the arterial pressure, at first during exercise and ultimately at rest. When this happens the body responds in the stereotyped manner for which it has been programmed by natural selection to maintain the arterial pressure during exercise or trauma.

In the short term this is achieved by autonomic regulation through the baroreflex arc, the central control of which is modulated by afferents from the limbs and instructions from higher centres. In the longer term the arterial pressure is maintained through an increase in the blood volume by retention of saline by the kidney. To this end local renal mechanisms are successively magnified by the reninangiotensin-aldosterone system and by the activity of the sympathetic system and vasopressin. In cardiac failure the natriuretic influence mediated through volume receptors and the release of atrial natriuretic peptide is overruled by the arterial baroreceptors so that the body maintains the arterial pressure at the expense of an increase in blood volume.

The increase in blood volume is, therefore, the result of "forward failure". But the distribution of the excess volume of blood is determined by the mechanical forces of "backward failure". Thus both these processes raise the pressure in the peripheral capillaries so that liquid is expelled into the tissue spaces to form oedema.

In these ways the arterial pressure has a central role in congestive cardiac failure and that syndrome may, with little exaggeration, be regarded primarily as one which arises when the heart is chronically unable to maintain an appropriate blood pressure without support.

I am glad to acknowledge the longstanding support of the British Heart Foundation.

\section{References}

1 Hope J. A treatise on the diseases of the heart and great vessels, and on the affections which may be taken for them: comprising the author's view of the physiology of the heart's action and sounds. London: John Churchill, 1832.

2 Starling EH. On the absorption of fluids from the connective tissue spaces. $J$ Physiol 1896;19:312-26.

3 Mackenzie J. Diseases of the heart. 3rd ed. Oxford Medical Publications, 1913:26.

4 Fahr G, Ershler I. Studies of factors concerned in edema formation. II. The hydrostatic pressure in the capillaries during edema formation in right heart failure. Ann Intern Med 1941;15:798-810.

5 Keith NM, Rowntree LG, Geraghty JT. A method for the determination of plasma and blood volume. Arch Intern Med 1915;16:547-76.
6 Wollheim E. Die Zirkulierende blutmenge und ihre bedeutung für kompensation und dekompensation des kreislaufs. $Z$ Klin Med 1931;116:269-397.

7 Starr I, Rawson AJ. Rôle of the "static blood pressure" in abnormal increments of venous pressure, especially in heart failure. I. Theoretical studies on an improved circulation schema whose pumps obey Starling's law of the heart. Am J Med Sci 1940;199:27-39.

8 Starr I. Rôle of the "static blood pressure" in abnormal increments of venous pressure, especially in heart failure. II. Clinical and experimental studies. Am J Med Sci 1940;199:40-55.

9 Wood PW. Diseases of the heart and circulation. Philadelphia: Lippincott, 1956.

10 Hickman JB, Cargill WH. Effect of exercise cardiac output and pulmonary arterial pressure in normal persons and in patients with cardiovascular disease and pulmonary emphysema. $J$ Clin Invest 1948;27:10-23.

11 Starling EH. The Linacre lecture on the law of the heart given at Cambridge, 1915. London: Longmans, Green, 1918.

12 Hamilton WF, Richards DW. The output of the heart. In: Fishman AP, Richards DW, eds. Circulation of the blood. Men and ideas. New York: Oxford University Press, 1965:71-126.

13 Sarnoff SJ, Berglund E. Ventricular function. I. Starling's law of the heart studied by means of simultaneous right and left ventricular curves. Circulation 1954;9:706-18.

14 Chidsey CA, Harrison DC, Braunwald E. The augmentation of plasma norepinephrine response to exercise in patients with congestive heart failure. $N$ Engl J Med 1962;267:650-4.

15 Chidsey CA, Braunwald E, Morrow AG. Catecholamine excretion and cardiac stores of norepinephrine in congestive heart failure. $\mathrm{Am} \mathrm{J} \mathrm{Med}$ 1965;39:442-51.

16 Wade OL, Bishop JM. Cardiac output and regional blood flow. Oxford: Blackwell, 1962.

17 Dittmar C. Ein Neurer Beweiss fur die Reizbarkeit de Centripetalen fasern des Ruckenmarks. Ber Sächs Ges Wiss 1870;22:18-45.

18 Owsjannikow P. Die tonischen und reflektorischen centren der gefässnerven. Ber Sächs Ges Wiss 1871;23:135-47.

19 Dittmar C. Uber die Loge des Sogenannten Gefässcentrums der Medulla Oblongata. Ber Sächs Ges Wiss 1873;25:449.

20 Schläfke $M$, Löschke $H H$. Lokalization eines au der regulation von atmung und kreislauf beteiligten gebiets an der ventralen oberfloeche der medulla oblongata durch kalteblockade. Pflugers Arch 1967;297:201-20.

21 Feldberg W, Guertzenstein PG. A vasodepressor effect of pentobarbitone sodium. J Physiol (Lond) 1972;224:83-103.

22 Feldberg $W$, Guertzenstein PG. Vasodepressor effect obtained by drugs acting on the ventral surface of the brain stem. J Physiol (Lond) 1976;258:337-55.

23 Hökfelt $T$, Fuxe K, Goldstein $M$, Johansson $O$. 
Congestive cardiac failure: central role of the arterial blood pressure

Immunohistochemical evidence for the existence of adrenaline neurons in the rat brain. Brain Res 1974;66:235-51.

24 Ross CA, Armstrong DM, Ruggiero DA, Pickel VM, Joh TH, Reis DJ. Adrenaline neurons in the rostral ventrolateral medulla innervate thoracic spinal cord. Neurosci Lett 1981;25:257-62.

25 Ross CA, Ruggiero DA, Park DH, et al. Tonic vasomotor control by the rostral ventrolateral medulla: effect of electrical or chemical stimulation of the area containing $\mathrm{Cl}$ adrenaline neurons on arterial pressure, heart rate and plasma catecholamines and vasopressin. J Neurosci 1984;4:479-94.

26 Granata AR, Ruggiero DA, Park DH, John TH, Reis DJ. Brain stem area with epinephrine neurons mediates baroreflex vasopressor responses. $A m \mathrm{~J}$ Physiol 1985;248:H547-67.

27 Blessing WW, Reis DJ. Inhibitory cardiovascular function of neurons in the caudal ventrolateral medulla of the rabbit: relationship to the area containing Al noradrenergic neurons. Brain Res 1982;253:161-71.

28 Imaizumi T, Granata AR, Benarroch EE, Sved AE, Reis D. Contributions of arginine vasopressin and the sympathetic neurons system to the fulminating hypertension after destruction of caudal ventrolateral medulla of the rat. $J$ Hypertens 1985; 3:491-501.

29 Cajal RY. Histologie du système nerveuse de l'homme et des vertebres. Vol. 1. Paris: Maloine, 1909.

30 Bronk DW, Stella G. Afferent impulses in the carotid sinus nerve. I. The relation of the discharge from single end organs to arterial blood pressure. $J$ Cell Comp Physiol 1932;1:113-30.

31 Hilton SM. Central nervous origin of vasomotor tone. Adv Physiol 1980;8:1-12.

32 Swanson LW. Immunohistochemical evidence for a neurophysin-containing autonomic pathway arising in the paraventricular nucleus of the hypothalamus. Brain Res 1977;128:346-53.

33 Saper CB, Loewy AD, Swanson LW, Cowan WM. Direct hypothalamic-autonomic connections. Brain Res 1976;117:305-12.

34 Kannan H, Yamashita $H$. Connections of neurons in the region of the nucleus tractus solitarius with the hypothalamic paraventricular nucleus: their possible involvement in the neural control of cardiovascular system. Brain Res 1985;329:205-12.

35 Caverson MM, Ciriello J, Calavesu FR. Cardiovascular afferent inputs to neurons in the ventrolateral medulla projecting directly to the central autonomic area of the thoracic cord in the cat. Brain Res 1983;274:354-8.

36 Sawchenko PE, Swanson LW. A method for tracing biochemical defined pathways in the central nervous system using combined fluorescence retrogade transport and immunohistochemical techniques. Brain Res 1981;210:31-51.

37 Eckberg DL, Drabinsky M, Braunwald E. Defective cardiac parasympathetic control in patients with heart disease. $N$ Engl J Med 1971;285:877-83.

38 Higgins CB, Vatner SF, Eckberg DL, Braunwald E.
Alterations in the baroreceptor reflex in conscious dogs with heart failure. $J$ Clin Invest 1972;51:715-24.

39 Eckberg DL, Fletcher GF, Braunwald E. Influence of background autonomic activity upon the response to carotid sinus nerve stimulation in man [Abstract]. Am J Cardiol 1970;26:631.

40 Bristow JD, Brown EB Jr, Cunningham DJC, et al. Effect of bicycling on the baroreflex regulation of pulse interval. Circ Res 1971;28:582-92.

41 Greenberg TT, Richmond WH, Stocking RA, Gupta PD, Meehan JP, Henry JP. Impaired atrial receptor responses in dogs with heart failure due to tricuspid insufficiency and pulmonary artery stenosis. Circ Res 1973;32:424-33.

42 Zucker IH, Earle AM, Gilmore JP. The mechanism of adaptation of left atrial stretch receptors in dogs with congestive heart failure. $J$ Clin Invest 1977;60:323-31.

43 Chidsey CA, Kaister GA, Sonnenblick EH, Spann JF, Braunwald E. Cardiac norepinephrine stores in experimental heart failure in the dog. $J$ Clin Invest 1964;43:2386-93.

44 Chidsey CA, Braunwald E, Morrow AG. Catecholamine excretion and cardiac stores of norepinephrine in congestive heart failure. $\mathrm{Am} \mathrm{J} \mathrm{Med}$ 1965;39:442-51.

45 Chidsey CA, Sonnenblick EH, Morrow AG, Braunwald E. Norepinephrine stores and contractile force of papillary muscle from the failing heart. Circulation 1966;33:43-51.

46 Rupp H, Jacob R. The autonomic nervous system of the heart. In: Rupp $\mathrm{H}$, ed. The regulation of heart function. New York: Thieme, 1986:53-70.

47 Covell JW, Chidsey CA, Braunwald E. Reduction of the cardiac response to postganglionic sympathetic nerve stimulation in experimental heart failure. Circ Res 1966;19:51-6.

48 Bristow MR, Ginsburg R, Minobe W, et al. Decreased catecholamine sensitivity and $\beta$-adrenergic-receptor density in failing human hearts. $N$ Engl J Med 1982;307:205-11.

49 Warren JV, Stead EA Jr. Fluid dynamics in chronic congestive failure. Arch Intern Med 1944;73:138-47.

50 Merrill AJ. Edema and decreased renal blood flow in patients with chronic congestive heart failure: evidence of "forward failure" as primary cause of edema. J Clin Invest 1946;25:389-400.

51 Mokotoff R, Ross G, Leiter I. Renal plasma flow and sodium reabsorption and excretion in congestive heart failure. J Clin Invest 1948;27:1-9.

52 Briggs AP, Fowell DM, Hamilton WF, Remington JW, Wheeler NC, Winslow JW. Renal and circulatory factors in the edema formation of congestive heart failure. J Clin Invest 1948;27:810-7.

53 Bradley SE, Blake WD. Pathogenesis of renal dysfunction during congestive heart failure. $\mathrm{Am} \mathrm{J} \mathrm{Med}$ 1949;6:470-80.

54 Davis JO, Howell DS. Mechanisms of fluid and electrolyte retention in experimental preparations in dogs. II. With thoracic inferior vena cava con- 
striction. Circ Res 1953;1:171-8.

55 Shipley RE, Study RS. Changes in renal blood flow, extraction of inulin, glomerular filtration rate, tissue pressure and urine flow with acute alterations of renal artery blood pressure. Am J Physiol 1951;167:676-88.

56 Barger AC. The pathogenesis of sodium retention in congestive heart failure. Metabolism 1956;5:480-9.

57 Ludwig C. Nieren und Hambereitung. In: Wanger R, ed. Handworterbuch der Physiologie. Vol. 2. Braunschweig: Vieweg F \& Son, 1844:628-59.

58 Cirksena WJ, Dirks JH, Berliner RW. Effect of thoracic cava obstruction on response of proximal tubule sodium reabsorption to saline infusion. J Clin Invest 1966;45:179-86.

59 Earley LE, Martino JA, Friedler RM. Factors affecting sodium reabsorption by the proximal tubule as determined during blockade of distal sodium reabsorption. J Clin Invest 1966;45: 1668-84.

60 Schneider EG, Dresser TP, Lynch RE, Knox FG. Sodium reabsorption by proximal tubule of dogs with experimental heart failure. Am J Physiol 1971;220:952-7.

61 Stumpe KO, Sölle H, Klein H, Krück F. Mechanism of sodium and water retention in rats with experimental heart failure. Kidney Int 1973;4:309-17.

62 Auld RB, Alexander EA, Levinsky NG. Proximal tubular function in dogs with thoracic caval constriction. J Clin Invest 1971;50:2150-8.

63 Levy M. Effects of acute volume expansion and altered hemodynamics on renal tubular function in chronic caval dogs. J Clin Invest 1972;51:922-38.

64 Mandin H. Cardiac edema in dogs. Proximal tubular and renal function. Can J Physiol Pharmacol 1979;57:185-92.

65 Singer B, Werner J. Excretion of sodium-retaining substances in patients with chronic heart failure. Am Heart J 1953;45:795-801.

66 Axelrod BJ, Cates JE, Johnson BB, Luetscher JA Jr. Aldosterone in urine of normal man of patients with oedema. Br Med J 1955;i:196-9.

67 Davis JO. The physiology of congestive heart failure. In: Hamilton WF, Dow P, eds. Handbook of physiology. Section 2: vol 3: 2071-122. American Physiological Society, 1965.

68 Carpenter CCJ, Davis JO, Holman JE, Ayers CR, Bahn RC. Studies on the response of the transplanted kidney and the transplanted adrenal gland to thoracic inferior vena caval constriction. J Clin Invest 1961;40:196-204.

69 Yankopoulos NA, Davis JO, Kliman B, Peterson RE. Evidence that a humoral agent stimulates the adrenal cortex to secrete aldosterone in experimental secondary hyperaldosteronism. J Clin Invest 1959;38:1278-89.

70 Biron P, Koiw E, Nowaczynski W, Brouillet J, Genest J. Effects of intravenous infusion of valine-5angiotensin II and other pressor agents on urinary electrolytes and corticosteroids, including aldosterone. J Clin Invest 1961;40:338-47.

71 Goldblatt H, Lynch J, Hanzel RF, Summercille WW. Studies on experimental hypertension, I. The prod- uction of persistent elevation of systolic blood pressure by means of renal ischemia. J Exp Med 1934;59:347-79.

72 Skinner SL, McCubbin JW, Page IH. Control of renin secretion. Circ Res 1964;15:64-76.

73 Tobian L, Tomboulian A, Janacek J. The effect of high perfusion pressure on the granulation of juxtaglomerular cells in an isolated kidney. J Clin Invest 1959;38:605-10.

74 Blain EH, Davis JO, Witty RT. Renin release after haemorrhage and after suprarenal aortic constriction in dogs without sodium delivery to the macula densa. Circ Res 1970;27:1081-9.

75 Farhi ER, Cant JR, Barger AC. Interactions between intrarenal epinephrine receptors and the renal baroreceptor in the control of PRA in conscious dogs. Circ Res 1982;50:477-85.

76 Richardson D, Stella A, Leonetti G, Bartorelli A, Zanchetti A. Mechanisms of renal release on renin by electrical stimulation of the brainstem in the cat. Circ Res 1974;34:425-34.

77 Natcheff N, Logofetov A, Tzaneva N. Hypothalmic control of plasma renin activity. Pflugers Arch 1977;371:279-83.

78 Jarechi M, Thoren PN, Donald DE. Release of renin by the carotid baroreflex in anaesthetised dogs. Circ Res 1978;42:614-9.

79 Thames MD, Jareski M, Donald DE. Neural control of renin secretion in anaesthetised dogs. Circ Res 1978;42:237-45.

80 Michelakis AN, McAllister RG. The effect of chronic adrenergic blockade on plasma renin activity in man. J Clin Endocrinol Metab 1972;34:386-94.

81 Bonelli J, Waldausl W, Magometchnigg D, Schwarzmeier J, Korn A, Hitzenberger G. Effect of exercise and of prolonged oral administration of propranolol on hemodynamic variables, plasma renin concentration, plasma aldosterone and cAMP. Eur J Clin Invest 1977;7:337-43.

82 Clamge DM, Sanford CS, Vander AJ, Mouw DR. Effects of psychosocial stimuli on plasma renin activity in rats. Am J Physiol 1976;231:1290-4.

83 Davalos M, Frega NS, Saker B, Leaf A. Effect of exogenous and endogenous angiotensin II in the isolated perfused rat kidney. Am J Physiol 1978;235:F605-10.

84 Watkins L Jr, Burton JA, Haber E, Cant JR, Smith FW, Barger AC. The renin-aldosterone system in congestive failure on conscious dogs. J Clin Invest 1976;57:1606-17.

85 Johnston CI, Davis JO, Robb CA, Mackenzie JW. Plasma renin in chronic experimental heart failure and during renal sodium "escape" from mineralocorticoids. Circ Res 1968;22:113-25.

86 Robinson FH Jr, Farr LE. Relation between clinical edema and the excretion of an anti diuretic substance in the urine. Ann Intern Med 1940;14:42-54.

87 Bercu BA, Rokaw SN, Massie E. Antidiuretic action of urine of patients in cardiac failure. Circulation 1950;2:409-13.

88 Yamane Y. Plasma ADH levels in patients with congestive failure. Jpn Circ J 1968;32:745-59. 
89 Anderson RJ, Cadnapaphornchai P, Harbottle JA, McDonald KM, Schrier RW. Mechanism of effect of thoracic inferior vena cava constriction on renal water excretion. J Clin Invest 1974;54:1473-9.

90 Arnauld E, Czernichow P, Fumoux F, Vincent JD. The effects of hypotension and hypovolemia on the liberation of vasopressin during hemorrhage in the unanesthetized monkey. Pflugers Archiv 1977; 371:193-200.

91 Gilmore JP, Zucker IH. Failure of left atrial distention to alter renal function in the nonhuman primate. Circ Res 1978;42:267-70.

92 de Bold AJ. Heart atria granularity. Effects of changes in water electrolyte balance. Proc Soc Exp Biol Med 1979;161:508-11.

93 de Bold AJ, Borenstein HB, Veress AT, Sonnenberg $H$. A rapid and potent natriuretic response to intravenous injection of atrial myocardial extract in rats. Life Sci 1981;28:89-94.

94 Atlas SA, Kleinert HD, Camargo MJ. Purification, sequencing and synthesis of natriuretic and vasoactive rat atrial peptide. Nature 1984;309:717-9.

95 Maki M, Takayanagi R, Misono KS, Pandey KN, Tibbetts C, Inagami $T$. Structure of rat atrial natriuretic factor precursor deduced from cDNA sequence. Nature 1984;309:722-4.

96 Trippodo NC, Ghai RD, MacPhee AA, Cole FE. Atrial natriuretic factor: atrial conversion of high to low molecular weight forms. Biochem Biophys Res Commun 1984;119:282-8.

97 Dietz JR. Release of natriuretic factor from rat heartlung preparations by atrial distension. Am J Physiol 1984;247:R1093-6.

98 Shanker Y, Sider RS, Ostafin EA, Grekin RJ. Plasma levels of immunoreactive atrial natriuretic factor in healthy subjects and in patients with oedema. J Clin Invest 1985;76:1684-7.

99 Briggs JP, Steipe B, Schubert G, Schnermann J. Micropuncture studies of the renal effects of atrial natriuretic substance. Pflugers Arch 1982;395: 271-6.

100 Grammer RT, Fukumi H, Inagami T, Mison KS. Rat atrial natriuretic factor. Purification and vasodilator activity. Biochem Biophys Res Commun 1983;116: 696-703.

101 Harris P. Evolution and the cardiac patient. Cardiovasc Res 1983;17:313-9,373-8,437-45.

102 Donald KW, Gloster J, Harris EA, Reeves J, Harris $P$. The production of lactic acid during exercise in normal subjects and in patients with rheumatic heart disease. Am Heart $J$ 1961;62:494-510.
103 Petro JM, Hollander AP, Bouman LN. Instantaneous cardiac acceleration in man induced by a voluntary muscle contraction. J Appl Physiol 1970;29:794-8.

104 Alam M, Smirk FH. Observations in man upon a blood pressure raising reflex from the voluntary muscles. J Physiol 1937;89:372-83.

105 Alam M, Smirk FH. Observations in man on a pulse accelerating reflex from the voluntary muscles of the legs. J Physiol (Lond) 1938;92:167-77.

106 Tibes U, Hemmer B, Böning D. Heart rate and ventilation in relation to venous $\left[\mathrm{K}^{+}\right]$, osmolality, $\mathrm{pH}$, $\mathrm{PCO}_{2}, \mathrm{Po}_{2}$, [orthophosphate], and [lactate] at transition from rest to exercise in athletes and nonathletes. Eur J Applied Physiol 1977;36:127-40.

107 Samet P, Fritts HW Jr, Fishman AP, Cournand A. The blood volume in heart disease. Medicine (Baltimore) 1957;36:211-35.

108 Dampney RAL, Goodchild AK, Robertson IG, Montgomery $W$. Role of ventrolateral medulla in vasomotor regulation: a correlative anatomical and physiological study. Brain Res 1982;249:223-35.

109 Gelsema AJ. A physiological review of mechanisms involved in the cardiovascular correlates of muscular activity. In: Grossman P, Janssen KHL, Vaitl $\mathrm{D}$, eds. Cardiorespiratory and cardiosomatic psychophysiology. New York: Plenum Press, 1986:41-55.

110 Liu CT, Huggins RA, Hoff HE. Mechanisms of intraarterial $\mathrm{K}^{+}$-induced cardiovascular and respiratory responses. Am J Physiol 1969;217:969-73.

111 Coote JH, Hilton SM, Perez-Gonzalez JF. The reflex nature of the pressor response to muscular exercise. J Physiol (Lond) 1971;215:789-804.

112 McCloskey DI, Mitchell JH. Reflex cardiovascular and respiratory responses originating in exercising muscle. $J$ Physiol (Lond) 1972;224:173-86.

113 Kalia M, Mei SS, Kao FF. Central projections from ergoreceptors (C fibers) in muscle involved in cardiopulmonary responses to static exercise. Circ Res 1981;48:48-62.

114 Sato A, Schmidt RF. Somatosympathetic reflexes: afferent fibers, central pathways, discharge characteristics. Physiol Rev 1973;53:916-47.

115 Schulz B, Lambertz $M$, Schulz G, Langhorst $P$. Reticular formation of the lower brainstem. A common system for cardiorespiratory and somatomotor fupctions: discharge patterns of neighboring neurons influenced by somotosensory afferents. J Auton Nerv Syst 1983;9:433-49.

116 Epstein FH, Post RS, McDowell M. Effects of an arteriovenous fistula on renal hemodynamics and electrolyte exertion. J Clin Invest 1953;32:233-41. 